\title{
Acute inflammation is a predisposing factor for weight gain and insulin resistance
}

Edson M. de Oliveira ${ }^{1,2^{*}}$, Jacqueline C. Silva ${ }^{1}$, Thais P. Ascar ${ }^{1}$, Silvana Sandri ${ }^{1}$, Alexandre F. Marchi ${ }^{1}$, Silene Migliorini ${ }^{1}$, Helder T. I. Nakaya ${ }^{1,3}$, Ricardo A. Fock $^{1}$, Ana Campa ${ }^{1}$

1Departamento de Análises Clínicas e Toxicológicas, Faculdade de Ciências Farmacêuticas, Universidade de São Paulo, 580 Lineu Prestes Avenue, São Paulo, SP, Brazil, 05508-000.

2University of Cambridge Metabolic Research Laboratories and NIHR Cambridge Biomedical Research Centre, Wellcome Trust-MRC Institute of Metabolic Science, Box 289, Addenbrooke's Hospital, Hills Road, Cambridge, CB2 0QQ, United Kingdom.

${ }^{3}$ Emory Vaccine Center, Yerkes National Primate Research Center, Emory University, Atlanta, GA 30329, USA.

${ }^{*}$ Corresponding author: Edson M. de Oliveira. Mailing address: University of Cambridge Metabolic Research Laboratories and NIHR Cambridge Biomedical Research Centre, Wellcome Trust-MRC Institute of Metabolic Science, Box 289, Addenbrooke's Hospital, Hills Road, Cambridge, CB2 0QQ, United Kingdom. Tel: +441223-762634. E-mail: em636@medschl.cam.ac.uk 


\section{ABSTRACT}

Aim

Intense endotoxaemia and infection are able to reduce appetite and induce a catabolic state, therefore leading to weight loss. However, it is underexplored its late effects on energy homeostasis, regulation of body weight and glucose metabolism. Here we addressed whether serial intense endotoxaemia, characterized by an acute phase response and weight loss, could be an aggravating or predisposing factor to diet-induced obesity (DIO) and associated metabolic impairments.

Methods

Male Swiss Webster mice were submitted to 8 consecutive doses of lipopolysaccharide (LPS - $10 \mathrm{mg} / \mathrm{kg}$ ), followed by 10 weeks in high-fat diet (HFD).

Results

After the end of the acute endotoxaemia period, mice under chow diet recovered their weight rapidly, within one-week recovery period, which remained similar to its control counterparts. However, acute endotoxaemia caused a long-lasting adipose tissue expression of the inflammatory markers TLR-4, CD14 and serum amyloid A (SAA) and, when challenged by a HFD, LPS-treated mice gained more weight, showed increased fat depots, leptin and insulin levels, and also impaired insulin sensitivity.

Conclusions

LPS-treated mice showed a higher susceptibility to the harmful effects of a subsequent HFD. Conditions leading to intense and recurrent endotoxaemia, such as common childhood bacterial infections, may resound for a long time 
and aggravate the effects of a western diet. If confirmed in humans, infections should be considered an additional factor contributing to obesity and type 2 diabetes epidemics and additionally impose more rigorous dietary recommendations for patients in post-infection recovery.

Keywords: Infection. Adipocyte. SAA. TLR-4. TLR-2. CD14.

Abbreviation list: cluster of differentiation 14 (CD14), glucose tolerance test (GTT), high-fat diet (HFD), insulin tolerance test (ITT), lipopolysaccharide (LPS), serum amyloid A (SAA), toll-like receptor 2 (TLR-2), toll-like receptor 4 (TLR-4).

\section{Bullet points.}

- Intense endotoxemia causes a long-lasting increase in the expression of inflammatory markers in adipose tissue.

- Intense endotoxemia is a predisposing factor to diet-induced obesity and insulin resistance.

- Infections may contribute to weight gain when associated to a western diet. 


\section{Introduction}

Metabolic endotoxaemia is the low-grade endotoxaemia derived from intestinal microbiota and modulated by high-fat feeding $(1,2)$. Since long-term endotoxaemia has a role in weight gain and insulin resistance, we hypothesized that a transient and intense endotoxaemia also impacts on adipose tissue and weight gain.

Intense endotoxaemia is observed along bacterial infections and it is experienced multiple times during human life. It is characterized by a large catabolic process that frequently leads to weight loss (3). In mice, endotoxaemia mimicking bacterial infections may be achieved by endovenous or intraperitoneal administration of high doses of lipopolysaccharide (LPS), resulting in a pronounced inflammatory response characterized by a huge increment in serum levels of acute phase proteins, such as serum amyloid $A$ (SAA) and C-reactive protein (CRP). Acute phase proteins are commonly used in clinical practice as an unspecific serum marker to confirm an inflammatory acute phase response. For instance, the serum levels of SAA may increase up to 1000 -fold compared to a non-inflammatory state (4). Although in this study SAA was used as an inflammatory marker, it is mandatory to consider that SAA affects adipose tissue biology (5) and may be considered as a trigger driving obesity and insulin resistance, as we recently showed using SAA-targeted antisense oligonucleotide in an experimental model of diet-induced obesity (6).

Although it is known that intense endotoxaemia is promptly associated with weight loss, here we wonder if acute endotoxaemia was able to prime the adipose tissue favouring a more pronounced response to an obesogenic stimulus. To reach our goal, we used an experimental model of multiple 
inductions of acute endotoxaemia (consecutive LPS challenges) followed by a HFD period. Also, in order to verify if acute infection could be correlated with cell proliferation, adipogenesis and inflammation in adipose tissue, therefore predisposing it for future hypertrophy, we performed a Gene Set Enrichment Analysis using a publicly database relative to the effect of gram-negative bacteria infections on adipose tissue.

If intense endotoxaemia leads to biochemical changes involved in adipose tissue hyperplasia and hypertrophy, acute inflammation should be recognized as an aggravating factor for weight gain and obesity comorbidities.

\section{Material and methods}

2.1 Animals. Male Swiss Webster mice (21 days of age) were obtained from the Animal Facility of the Faculty of Pharmaceutical Sciences, University of São Paulo, Brazil, under approval by its Ethical Committee (CEEA n²97). The animals were housed inside standard polypropylene cages in a room maintained at $22 \pm 2^{\circ} \mathrm{C}$ in $12: 12 \mathrm{~h}$ light/dark cycle (lights on at 7:00 am and off at 7:00 pm) and a relative humidity of $55 \pm 10 \%$. Body weight was measured once a week during the entire protocol. Food and water intake were kept ad libitum and were measured every 2 days. Euthanasia occurred by anaesthesia overdose and ensured by cervical dislocation.

\subsection{Acute endotoxaemia followed by recovery period under chow diet. The} method of multiple inductions of acute endotoxaemia comprises intraperitoneal administration of 8 consecutive injections (every 3 days) of LPS $10 \mathrm{mg} / \mathrm{kg}$ (Lipopolysaccharides from Escherichia coli 026:B6, Sigma-Aldrich ${ }^{\circledR}$, St. Louis, 
MO, USA), in saline ( $\mathrm{NaCl} 0,9 \%)$, starting at weaning (21 days of age) with end at 45 days of age of the animal. The time between two acute endotoxaemia (3 days) was defined by the SAA production profile. It was observed that after LPS injection, SAA concentration increases over a 100-times, with maximum values in 12 hours, approximately $1500 \mu \mathrm{g} / \mathrm{mL}$, with return to basal in 72 hours (Supplementary Table 1). For acute endotoxaemia experiments, mice were randomly assigned into 2 different groups: the Control and the LPS groups, with euthanasia occurring after the last acute phase period or after 6 weeks from the last acute phase induction (recovery period). The experimental design is illustrated in Supplementary Fig. 1a.

2.3 Acute endotoxaemia followed by High-Fat Diet (HFD). For acute endotoxaemia followed by 10 weeks on a high-fat diet (LPS+HFD) experiments, the animals were randomly assigned into 2 different groups: HFD group and LPS+HFD group. The HFD mice were submitted to a HFD for 10 weeks starting concurrently with the LPS+HFD group. The LPS+HFD mice were underwent to multiple inductions of acute endotoxaemia followed by 1 week of recovery period in standard chow diet plus 10 weeks on a $30 \%$ HFD. In our experimental model, we consider the recovery period as 7 days, been the time that we observed weight reestablishment. The diet was produced following the American Institute of Nutrition's recommendations for the adult rodent and its composition is listed in Supplementary Table 2. Body weight was measured every 3 days during acute phase period. The experimental design is illustrated in Supplementary Fig. 1b. 


\subsection{Glucose and insulin tolerance tests and measurements of serum} leptin, adiponectin, insulin, IGF-I, SAA and endotoxin. i.p. Glucose and insulin tolerance tests (IPGTT and IPITT) were performed as described previously (7). Serum concentrations of the proteins below were determined using ELISA following the manufacturer's instructions: leptin, adiponectin and insulin (Millipore ${ }^{\circledR}$ Corporation, Billerica, MA, USA), SAA (Tridelta Development Ltd, Maynooth, Ireland) and IGF-I (R\&D Systems ${ }^{\circledR}$, Minneapolis, MN, USA). Endotoxin was measured with the Limulus Amoebocyte Lysate (LAL) chromogenic end-point assay (Lonza ${ }^{\circledR}$, Allendale, NJ, USA).

2.5 Histological Analysis. Paraffin-embedded sections (5 $\mu \mathrm{m}$ thick) from epididymal adipose tissue were stained by haematoxylin and eosin to assess morphology. Immunohistochemistry for $\mathrm{F} 4 / 80^{+}$was performed using a rat antimouse $\mathrm{F} 4 / 80^{+}$antibody (1:100 dilution, AbD Serotec ${ }^{\circledR}$, Raleigh, NC, USA) subsequently incubated with the appropriate secondary biotinylated antibody (Vector Laboratories Inc., Burlingame, CA, USA) and visualized with Immpact AEC peroxidase (Vector Laboratories Inc., Burlingame, CA, USA). Immunofluorescence for $\mathrm{F} 4 / 80^{+}, \mathrm{SAA}$ and perilipin were performed using a rat anti-mouse $\mathrm{F} 4 / 80^{+}$antibody and rabbit anti-mouse perilipin (both 1:100 dilution, Abcam $^{\circledR}$, Cambridge, UK), and a rabbit anti-mouse SAA (1:200 dilution, kindly provided by Dr. de Beer laboratory, University of Kentucky, KY, USA), subsequently incubated with the appropriate secondary fluorescent antibody (Invitrogen ${ }^{\circledR}$, Camarillo, CA, USA) and the slides mounted using Vectashield set mounting medium with 4,6-diamidino-2-phenylindol-2-HCl (DAPI; Vector Laboratories Inc., Burlingame, CA, USA). An isotype control was used to 
ensure antibody specificity in each staining. Tissue sections were observed with a Nikon Eclipse 80i microscope $\left(\mathrm{Nikon}^{\circledR}\right)$ and digital images were captured with NIS-Element AR software $\left(\right.$ Nikon $\left.^{\circledR}\right)$.

2.6 In vivo peripheral fat area quantification. Two X-ray images were taken at different energy levels allowing circumscribe the adipose tissue on the animals as described previously (7).

2.7 Quantitative Real-Time PCR. Total RNA from epididymal adipose tissue was isolated using Qiagen RNeasy ${ }^{\circledR}$ Lipid Tissue Mini kit (Qiagen, Hilden, Germany). cDNA was then synthesized from $1 \mu \mathrm{g}$ of RNA using the High Capacity cDNA Reverse Transcription (Life Technologies ${ }^{\circledR}$, Grand Island, NY, USA). Real-time PCR were performed using SyBr ${ }^{\circledR}$ Green Master Mix (Life Technologies $^{\circledR}$, Grand Island, NY, USA). The primer sequences are detailed in Supplementary Table 3. Real-time PCR for Saa3 was performed using the TaqMan $^{\circledR}$ assay (Applied Biosystems ${ }^{\circledR}$, Grand Island, NJ, USA), catalogue number Mm00441203_m1 - Saa3 and $\beta$-actin (Actb), number 4552933E, as an endogenous housekeeping gene control. Relative gene expression was determined using the $2^{-\Delta \Delta \mathrm{Ct}}$ method.

\subsection{Gene Set Enrichment Analysis of publicly available microarray data.}

We collected from GEO (http://www.ncbi.nlm.nih.gov/geo, GSE50647) the expression profiles of mouse visceral adipose tissue. In the study (8), authors exposed chow-fed apolipoprotein $E$ (apoE) deficient mice to either 1) recurrent intravenous infection with $A$. actinomycetemcomitans or 2) a combination of 
recurrent intravenous infection with $A$. actinomycetemcomitans with a chronic intranasal infection with C. pneumonia. For the Gene Set Enrichment Analysis (GSEA) we ranked genes based on their mean $\log _{2}$ fold-change values between infected compared to uninfected mice. We then utilized custom gene sets, which contained genes related to: proliferation, adipogenesis, inflammation and SAA family. GSEA was performed using default parameters. Heat maps were used to display all genes from a statistically significant gene set.

2.9 Statistical analysis. Results were presented as mean \pm SEM. Statistical analysis was performed with Graph Pad Prism4 (Graph Pad Software, Inc., San Diego, CA, USA). Comparisons between two groups were conducted with the unpaired Student's $t$ test. Data with two independent variables were tested by two-way analysis of variance with Bonferroni post hoc test. The level of significance was set at ${ }^{*} p<0.05$.

\section{Results}

\subsection{Acute endotoxaemia affects adipose tissue but does not lead to mice weight gain under chow diet.}

In order to verify the effect of acute endotoxaemia in adipose tissue, mice were subjected to 8 consecutives LPS challenges, every 3 days (Supplementary Fig. 1a). During the acute phase response, endotoxin (Fig. 1a) and SAA (Fig. 1b) levels raised over a hundredfold in serum and mice developed overt signs of endotoxaemia (hunched posture, reduced movement and piloerection) with no animal death. It is known that acute endotoxaemia 
change food intake behaviour causing a reduced food intake and leading to weight loss. During the acute endotoxaemia period, LPS animals showed a reduced caloric intake (up to $40 \%$ lower; Fig. 1c), causing weight loss (approx. $12.5 \%$ of their total weight; Fig. $1 \mathrm{~d}$ ) and $20 \%$ of epididymal adipose tissue mass (Fig. 1e).

By the histological analysis from epididymal adipose tissue (Fig. 1I), it was also possible to verify a decrease in $30 \%$ of the adipocyte size in the LPS group (Fig. 1f). Besides weight loss, mice had increased inflammatory markers, such as macrophage infiltration $\left(\mathrm{F} 4 / 80^{+}\right.$cells, Fig. 1l) and Saa3 mRNA expression (Fig. 1h) without Saa1.1 and Saa2.1 modulation in adipose tissue (Fig. 1g). The expression of TIr-4 (Fig. 1j) and Cd14 (Fig. 1k) had an increase of more than three times, although the T/r-2 (Fig. 1i) remained unaltered.

During the experimental protocol, no tolerance to LPS was observed, with increment in serum endotoxin (Supplementary Figure 2a) and SAA (Supplementary Figure $2 b$ ) remaining similar after each LPS challenge. After the endotoxaemia period, the animals recovered their weight in the course of a week without showing any difference from Control group in the 42 consecutive days (6 weeks) (Fig. 1c and d). One week after the last LPS challenge (LPS + REC) was also sufficient for the reestablishment of serum levels of endotoxin (Fig 1a) and SAA (Fig 1b), however, the expression of Saa3 (Fig 1h), T/r-4 (Fig 1j) and Cd14 (Fig 1k) remained augmented in the adipose tissue.

\subsection{A previous history of acute endotoxaemia exacerbates HFD complications.}


After the LPS challenges and a recovery period of one week, mice were submitted to a HFD for 70 days (10 weeks) (Supplementary Fig. 1b). HFD-fed mice without having previously been submitted to LPS challenges were used as controls. The shift of chow diet to HFD resulted in an increment of approximately twice in the caloric intake for both groups, HFD and LPS+HFD (Fig. 2a). Despite the similar caloric intake between these groups, mice previously submitted to multiple LPS challenges (LPS+HFD) showed a different growth curve with increased total body weight (approximately in 15\%) (Fig. 2b), with increased epididymal (Fig. 2c) and subcutaneous (Fig. 3e) adipose tissue depots, and no difference in retroperitoneal (Fig. 3d) fat. The data were confirmed using X-rays images highlighting the subcutaneous fat area on the animals, showing that LPS+HDF mice have a higher peripheral fat area, an increment in $23 \%$ in adipose tissue (Fig. $2 f$ and g). Besides that, the epididymal fat from LPS+HFD mice presented larger adipocytes than HFD group (Fig. 2h), that may explain the metabolic phenotype. On the other hand, there is no difference in the adipose tissue inflammatory profile, showing similar macrophage infiltration $\left(\mathrm{F} 4 / 80^{+}\right)$and SAA production (Fig. $\left.2 \mathrm{i}\right)$ in both HFD and LPS+HFD groups. However, it is important to highlight that all aforementioned parameters (adipocyte hypertrophy, macrophage infiltration and SAA production in the adipose tissue) are increased when compared to lean control group (under chow diet) (Fig. 2i).

Under a high-fat diet, the endotoxin and SAA concentration reach serum levels about twice from that observed in lean mice (Fig. 3a compared to 1a and Fig. $3 b$ compared to $1 b)$ without differences between HFD and LPS+HFD groups. In a similar manner, transcript levels of Saa3 increases upon HFD 
induction regardless previous administration of LPS (Fig. 3d compared to $1 \mathrm{~h}$ ). The adipose tissue expression of Saa1.1/Saa2.1 was similar among all conditions (Fig. 3C compared to Fig. 1g). Nevertheless, mice previously submitted to multiple LPS challenges showed an increment in TIr-4 (Fig. 3f) and Cd14 (Fig. 3g) mRNA expression in the adipose tissue, with no change in TIr2 transcript levels (Fig. 3e). Also, mice previously submitted to multiple acute endotoxaemia had a worsened metabolic profile after the DIO protocol, with an increase in leptin (Fig. 3h) and insulin (Fig. 3I) levels, with impaired glucose homeostasis as observed by the notably affected glucose and insulin tolerance tests (Fig. 3m and 3n). Adiponectin (Fig. 3i), IGF-1 (Fig. 3j) and fasting glucose (Fig. 3k) concentrations were also measured in serum and no significant difference were observed.

\subsection{Recurrent infection upregulates proliferative and inflammatory genes in adipose tissue.}

We looked at the GEO database for studies similar to our experimental protocol and where it was performed transcriptome analysis in mice adipose tissue. From the study GSE50647 (8), where mice were infected with gramnegative bacteria ( $A$. actinomycetemcomitans or coinfected with $A$. actinomycetemcomitans and C. pneumonia), it was observed that a group of genes responsible for driving proliferation and inflammation were upregulated after infection, as well as SAA-related genes (SAA isoforms and receptors). On the other hand, the cluster of genes involved in adipogenesis was downregulated (Fig. 4). 


\section{Discussion}

Here we report that, besides the concurrent effects, multiple and intense endotoxaemia also causes long lasting biochemical alterations in the adipose tissue that may intensify the harmful effects of a subsequent introduced highfat diet. Adipose tissue expression of T/r-4, Cd14 and Saa3 were increased in mice submitted to multiple and severe endotoxaemia and persisted even after the end of LPS challenges. Accordingly, acute endotoxaemia, and consequently acute inflammation, should be recognized as an aggravating factor for weight gain and insulin resistance derived from a fat-enriched diet.

The intense and transient endotoxaemia detected in our experimental protocol, led to an approximately 150-times increment in endotoxin serum levels (reaching values near to $300 \mathrm{EU} / \mathrm{mL}$ ) is comparable to levels found in mice and humans during infectious processes and other diseases (9). Endotoxaemia induces the release of a large amount of inflammatory mediators, such as proinflammatory cytokines and highly reactive oxygen and nitrogen intermediates identified as contributors to the LPS-induced tissue damage $(10,11)$. The plasma level of the acute phase protein SAA increased near 1000 times and returned to basal levels after 72 hours in each LPS dose (Supplementary Table 1). During the endotoxemic phase the food intake dramatically dropped and a perceptible and expected depletion in fat depots and appearance of smaller adipocytes occurred (Fig. 1e and 3f). Besides SAA, other inflammatory markers raised in adipose tissue after the serial LPS challenges, including macrophage infiltration and T/r-4 and Cd14 mRNA expression. The rapid recovery of weight and maintenance of the growth curve after the suspension of endotoxaemia tells us that the modifications derived 
from the acute phase, by itself, did not compromise the adipose tissue homeostasis. However, when we introduced a high-fat diet the harmful metabolic repercussions were clearly more pronounced.

TLR-4 and its co-receptor CD14 are associated with diet-induced obesity and insulin resistance in mice $(1,12,13)$. The observed persistent increment in TIr-4 and Cd14 expression in adipose tissue after LPS treatment may be one of the keys to explain the more severe weight gain and glucose homeostasis impairment. It is known that LPS and nutritional fatty acids activate TLR-4 and the co-receptor CD14 triggering the secretion of proinflammatory cytokines (1416). This is probably one of the elements in the inflammatory signalling cascade in adipose tissue linked to metabolic diseases. Thus, the simple fact that the levels of $T / r-4$ and $C d 14$ mRNA remains elevated after the interruption of acute endotoxaemia could support the higher adipose tissue responsiveness to a HFD.

Also, it is known that TLR-2 deficiency protects mice from insuin resistance and reduces tissue inflammation induced by a high-fat diet, in a process dependent of the microbiota (17). Although the expression of TLR-2 was not changed in our model of acute endotoxaemia, it is conceivable to speculate that the interaction between TLR-2 and TLR-4 might be affected, modulating its receptor cooperation and further cellular response to LPS (18).

The mechanism by which acute endotoxaemia leads to more severe consequences arising from a HFD is undoubtedly complex and may encompasses a diversity of factors. Possible endogenous TLR-4 and TLR-2 ligands involved in the signalling of acute inflammation and associate to the control of body weight may also play a role in this process. For instance, SAA 
is a TLR2 and TLR4 agonist $(19,20)$ and its serum levels are positively correlated with the obesity grade (21). Moreover, although SAA is predominantly synthesized by the liver in acute inflammation, adipocytes are known producers of SAA and the mRNA and protein levels are modulated under hypoxic conditions $(22,23)$, a common event during adipose tissue expansion. SAA production is associated with a pro-inflammatory response and also with promotion of proliferation in different cell types $(5,20,24-32)$. Besides that, data from SAA KO mice $(32,33)$ and studies using SAA antisense oligonucleotide $\left(\mathrm{ASO}_{\mathrm{SAA}}\right)(6,34)$ strongly support that SAA is part of the LPS signalling linking inflammation to obesity and insulin resistance.

In order to evaluate the comprehensiveness of some of our conclusions, especially that related to the hypothesis that acute inflammation induces preadipocyte proliferation while triggering SAA production, we performed a Gene Set Enrichment Analysis in a publicly available microarray data (GSE50647) (8) from a study in which mice were infected with gram-negative bacteria. We identified that different clusters of genes responsible for driving proliferation, inflammation and SAA-related genes (SAA isoforms and receptors) were upregulated, while genes involved in adipogenesis were downregulated after infection. Thus, the cell proliferation that occurs in adipose tissue during an infection process may provide the right condition for future susceptibility to a DIO protocol.

Considering that epidemiological data shows that low-income children have a higher prevalence of infectious diseases and are more susceptible to obesity $(35,36)$, is inevitable to consider that excess body weight in adults may be associated with an inflammatory state during childhood. Although obesity is 
to a large extend a lifestyle disease, the current scientific literature has shown previous unsuspected factors contributing to obesity development. For instance, viral infections have been linked to obesity, particularly by the human adenovirus-36 (37). In humans, anti-Ad-36 antibodies are more prevalent in obese subjects $(30 \%)$ than in non-obese (11\%) (38). Despite differences between viral and bacterial infections it is legitimate to assume that both types of infection share some major signalling pathways linking them to obesity, such as the upregulation of TLR-4 and SAA $(39,40)$.

In conclusion, our data describes that conditions leading to inflammation may resound for a long time in mice. If it is confirmed in humans, infections may contribute to obesity and type 2 diabetes epidemics when associated with a western diet. Furthermore, our results indicate that a more severe dietary recommendation for patients in post-infection recovery should be considered. 
Acknowledgements. The authors thank the technical support from Ed Wilson Cavalcante Oliveira Santos of the University of São Paulo.

Funding. This study was supported by Fundação de Amparo à Pesquisa do Estado de São Paulo (FAPESP) (grant number 2011/24052-4 and 2010/184987 [doctoral scholarship]), Coordenação de Aperfeiçoamento de Pessoal de Nível Superior (CAPES) and Conselho Nacional de Desenvolvimento Científico e Tecnológico (CNPq) (grant number 47510/2010-6).

Duality of Interest. No conflicts of interest, financial or otherwise, are declared by the authors.

Contribution Statement. E.M.O. contributed to the study conception and design, performing experiments, acquisition and interpretation of data and the manuscript writing. J.C.S., T.P.A, S.S., A.F.M and S.M. performed some experiments. H.T.I.N. design experiments and interpreted data. R.A.F. designed experiments and A.C. contributed to the study conception and design, interpretation of data and the manuscript writing. 


\section{FIGURE LEGENDS}

Figure 1. Acute endotoxaemia affects adipose tissue but does not lead to mice weight gain under chow diet. Swiss Webster mice were submitted to i.p. administration of 8 consecutive doses of $10 \mathrm{mg} / \mathrm{kg}$ LPS, every 3 days. (a) Endotoxin and (b) SAA concentration in serum. (c) Daily caloric intake. (d) Weight gain curve of Control and LPS mice. The vertical dashed line in $c$ and $d$ indicate the end of acute endotoxaemia period. (e) Epididymal fat pad weight. (f) Epididymal adipocyte size. (g-k) Quantitative Real-Time PCR was performed to assess mRNA expression of (g) Saa1.1/2.1, (h) Saa3, (i) T/r-2, (j) TIr-4 and (k) Cd14 in epididymal adipose tissue. (l) Histological sections of epididymal fat pads after LPS challenges showing adipocyte morphology on haematoxylin and eosin staining and macrophage infiltration $\left(\mathrm{F} 4 / 80^{+}\right)$. Data are means \pm SEM from 6 mice per group $\left({ }^{*} p<0.05,{ }^{* *} p<0.01,{ }^{* *} p<0.001\right.$, between groups, as indicated).

Figure 2. A previous history of acute endotoxaemia potentiates weight gain induced by a HFD. Mice Swiss Webster were submitted to i.p. administration of 8 consecutive doses of $10 \mathrm{mg} / \mathrm{kg}$ LPS, every 3 days, followed by 10 weeks in HFD. (a) Daily caloric intake, including the diet switch after acute endotoxaemia period. (b) Weight gain curve of HFD and LPS+HFD groups. (c) Epididymal, (d) Retroperitoneal and (e) Subcutaneous fat pad weight after HFD period. (f) subcutaneous fat area quantification in HFD and LPS+HFD mice after HFD period. (g) Representative fat area quantification. (h) Adipocyte size after HFD period. (i) Histological sections of epididymal fat pads after HFD 
periods showing adipocyte morphology on haematoxylin and eosin staining, macrophage infiltration $\left(\mathrm{F} 4 / 80^{+}\right)$and SAA production. Data are means \pm SEM from 8 mice per group $\left({ }^{*} p<0.05,{ }^{* *} p<0.01,{ }^{* * *} p<0.001\right.$, between groups, as indicated).

Figure 3. A previous history of acute endotoxaemia potentiates glucose tolerance and insulin resistance induced by a HFD. After the HFD period, mice previously submitted to multiple acute endotoxaemia were evaluated regarding its metabolic parameters. Determination of (a) endotoxin and (b) SAA in serum. (c-g) Quantitative Real-Time PCR for mRNA expression of (c) Saa1.1/2.1 (d) Saa3, (e) TIr-2, (f) T/r-4 and (g) Cd14 in adipose tissue. (h-l) At last, the measurement of (h) leptin, (i) adiponectin, (j) IGF-I, (k) fasting glucose and (I) insulin in serum. (m) i.p. glucose tolerance test (IPGTT) and (n) i.p. insulin tolerance test (IPITT). Data are means \pm SEM from 8 mice per group $\left({ }^{*} p\right.$ $<0.05,{ }^{* *} p<0.01$, between groups, as indicated).

Figure 4. Recurrent infection modulates proliferative, adipogenic, inflammatory and SAA-related genes in adipose tissue. Gene Set Enrichment Analysis (GSEA) revealed that proliferative, adipogenic, inflammatory and SAA-related gene sets in mouse adipose tissue were significantly associated (nominal $p$-value $<0.05$ ) with infection with $A$. actinomycetemcomitans or co-infection with $A$. actinomycetemcomitans and $C$. pneumonia (see methods for details). Heat maps show the mean $\log _{2}$ foldchange of all genes of each gene set on each condition compared to uninfected mice. 


\section{REFERENCES}

1. Cani PD, Amar J, Iglesias MA, Poggi M, Knauf C, Bastelica D, Neyrinck AM, Fava F, Tuohy KM, Chabo C, Waget A, Delmee E, Cousin B, Sulpice T, Chamontin B, Ferrieres J, Tanti JF, Gibson GR, Casteilla L, Delzenne NM, Alessi MC, Burcelin R. Metabolic endotoxemia initiates obesity and insulin resistance. Diabetes 2007; 56:1761-1772

2. Cani PD, Bibiloni R, Knauf C, Neyrinck AM, Delzenne NM, Burcelin R. Changes in gut microbiota control metabolic endotoxemia-induced inflammation in high-fat diet-induced obesity and diabetes in mice. Diabetes 2008; 57:1470-1481

3. Gabay C, Kushner I. Mechanisms of disease: Acute-phase proteins and other systemic responses to inflammation. New England Journal of Medicine 1999; 340:448-454

4. Urieli-Shoval S, Linke RP, Matzner Y. Expression and function of serum amyloid A, a major acute-phase protein, in normal and disease states. Current Opinion in Hematology 2000; 7:64-69

5. Filippin-Monteiro FB, de Oliveira EM, Sandri S, Knebel FH, Albuquerque RC, Campa A. Serum amyloid A is a growth factor for 3T3-L1 adipocytes, inhibits differentiation and promotes insulin resistance. International Journal of Obesity 2012; 36

6. de Oliveira EM, Ascar TP, Silva JC, Sandri S, Migliorini S, Fock RA, Campa A. Serum amyloid A links endotoxaemia to weight gain and insulin resistance in mice. Diabetologia 2016; 59:1760-1768

7. de Oliveira EM, Visniauskas B, Sandri S, Migliorini S, Andersen ML, Tufik S, Fock RA, Chagas JR, Campa A. Late effects of sleep restriction: Potentiating weight gain and insulin resistance arising from a high-fat diet in mice. Obesity 2015; 23:391-398

8. Hyvarinen $\mathrm{K}$, Tuomainen AM, Laitinen S, Alfthan G, Salminen I, Leinonen M, Saikku P, Kovanen PT, Jauhiainen M, Pussinen PJ. The effect of proatherogenic pathogens on adipose tissue transcriptome and fatty acid distribution in apolipoprotein E-deficient mice. Bmc Genomics 2013; 14

9. Nymark M, Pussinen PJ, Tuomainen AM, Forsblom C, Groop P-H, Lehto M, Finndiane Study G. Serum Lipopolysaccharide Activity Is Associated With the Progression of Kidney Disease in Finnish Patients With Type 1 Diabetes. Diabetes Care 2009; 32:1689-1693

10. Russell JA. Drug therapy: Management of sepsis. New England Journal of Medicine 2006; 355:1699-1713

11. Cohen J. The immunopathogenesis of sepsis. Nature 2002; 420:885-891

12. Song MJ, Kim KH, Yoon JM, Kim JB. Activation of Toll-like receptor 4 is associated with insulin resistance in adipocytes. Biochemical and Biophysical Research Communications 2006; 346:739-745

13. Kim K-A, Gu W, Lee I-A, Joh E-H, Kim D-H. High Fat Diet-Induced Gut Microbiota Exacerbates Inflammation and Obesity in Mice via the TLR4 Signaling Pathway. Plos One 2012; 7

14. Shi H, Kokoeva MV, Inouye K, Tzameli I, Yin H, Flier JS. TLR4 links innate immunity and fatty acid-induced insulin resistance. Journal of Clinical Investigation 2006; 116:3015-3025 
15. Schaffaeler A, Schoelmerich J. Innate immunity and adipose tissue biology. Trends in Immunology 2010; 31:228-235

16. Lin $Y$, Lee $H$, Berg AH, Lisanti MP, Shapiro L, Scherer PE. The lipopolysaccharide-activated toll-like receptor (TLR)-4 induces synthesis of the closely related receptor TLR-2 in adipocytes. Journal of Biological Chemistry 2000; 275:24255-24263

17. Ehses JA, Meier DT, Wueest S, Rytka J, Boller S, Wielinga PY, Schraenen A, Lemaire K, Debray S, Van Lommel L, Pospisilik JA, Tschopp 0, Schultze SM, Malipiero U, Esterbauer H, Ellingsgaard H, Rutti S, Schuit FC, Lutz TA, BoniSchnetzler M, Konrad D, Donath MY. Toll-like receptor 2-deficient mice are protected from insulin resistance and beta cell dysfunction induced by a high-fat diet. Diabetologia 2010; 53:1795-1806

18. Laflamme N, Echchannaoui H, Landmann R, Rivest S. Cooperation between toll-like receptor 2 and 4 in the brain of mice challenged with cell wall components derived from gram-negative and gram-positive bacteria. European Journal of Immunology 2003; 33:1127-1138

19. Cheng N, He R, Tian J, Ye PP, Ye RD. Cutting edge: TLR2 is a functional receptor for acute-phase serum amyloid A. Journal of Immunology 2008; 181:22-26

20. Sandri S, Rodriguez D, Gomes E, Monteiro HP, Russo M, Campa A. Is serum amyloid A an endogenous TLR4 agonist? Journal of Leukocyte Biology 2008; 83:1174-1180

21. Zhao YL, He XL, Shi XG, Huang CJ, Liu J, Zhou SL, Heng CK. Association between serum amyloid $A$ and obesity: a meta-analysis and systematic review. Inflammation Research 2010; 59:323-334

22. Eklund KK, Niemi K, Kovanen PT. Immune Functions of Serum Amyloid A. Critical Reviews in Immunology 2012; 32:335-348

23. de Oliveira EM, Sandri S, Knebel FH, Iglesias Contesini CG, Campa A, Filippin-Monteiro FB. Hypoxia Increases Serum Amyloid A3 (SAA3) in Differentiated 3T3-L1 Adipocytes. Inflammation 2013; 36:1107-1110

24. Furlaneto CJ, Campa A. A novel function of serum amyloid A: A potent stimulus for the release of tumor necrosis factor-alpha, interleukin-1 beta, and interleukin- 8 by human blood neutrophil. Biochemical and Biophysical Research Communications 2000; 268:405-408

25. Hatanaka E, Ribeiro FP, Campa A. The acute phase protein serum amyloid A primes neutrophils. Fems Immunology and Medical Microbiology 2003; 38:81-84

26. Hatanaka E, Dermargos A, Armelin HA, Curi R, Campa A. Serum amyloid A induces reactive oxygen species (ROS) production and proliferation of fibroblast. Clinical and Experimental Immunology 2011; 163

27. Knebel FH, Albuquerque RC, Massaro RR, Maria-Engler SS, Campa A. Dual Effect of Serum Amyloid A on the Invasiveness of Glioma Cells. Mediators of Inflammation 2013;

28. Niemi K, Teirila L, Lappalainen J, Rajamaki K, Baumann MH, Oorni K, Wolff H, Kovanen PT, Matikainen S, Eklund KK. Serum Amyloid A Activates the NLRP3 Inflammasome via P2X(7) Receptor and a Cathepsin B-Sensitive Pathway. Journal of Immunology 2011; 186:6119-6128

29. Ather JL, Ckless K, Martin R, Foley KL, Suratt BT, Boyson JE, Fitzgerald KA, Flavell RA, Eisenbarth SC, Poynter ME. Serum Amyloid A Activates the 
NLRP3 Inflammasome and Promotes Th17 Allergic Asthma in Mice. Journal of Immunology 2011; 187:64-73

30. Badolato R, Wang JM, Murphy WJ, Lloyd AR, Michiel DF, Bausserman LL, Kelvin DJ, Oppenheim JJ. SERUM AMYLOID-A IS A CHEMOATTRACTANT INDUCTION OF MIGRATION, ADHESION, AND TISSUE INFILTRATION OF MONOCYTES AND POLYMORPHONUCLEAR LEUKOCYTES. Journal of Experimental Medicine 1994; 180:203-209

31. Faty A, Ferre P, Commans S. The Acute Phase Protein Serum Amyloid A Induces Lipolysis and Inflammation in Human Adipocytes through Distinct Pathways. Plos One 2012; 7

32. den Hartigh LJ, Wang SR, Goodspeed L, Ding YL, Averill M, Subramanian S, Wietecha T, O'Brien KD, Chait A. Deletion of Serum Amyloid A3 Improves High Fat High Sucrose Diet-Induced Adipose Tissue Inflammation and Hyperlipidemia in Female Mice. Plos One 2014; 9

33. De Beer MC, Wroblewski JM, Noffsinger VP, Rateri DL, Howatt DA, Balakrishnan A, Ji A, Shridas P, Thompson JC, van der Westhuyzen DR, Tannock LR, Daugherty A, Webb NR, De Beer FC. Deficiency of Endogenous Acute Phase Serum Amyloid A Does Not Affect Atherosclerotic Lesions in Apolipoprotein E-Deficient Mice. Arteriosclerosis Thrombosis and Vascular Biology 2014; 34:255-261

34. de Oliveira EM, Visniauskas B, Tufik S, Andersen ML, Chagas JR, Campa A. Serum Amyloid A Production Is Triggered by Sleep Deprivation in Mice and Humans: Is That the Link between Sleep Loss and Associated Comorbidities? Nutrients 2017; 9

35. Singh GK, Siahpush M, Kogan MD. Rising social inequalities in U.S. childhood obesity, 2003-2007. Vol 20: Annals of Epidemiology; 2010:4052 .

36. Singh AR, Singh SA. Diseases of Poverty and Lifestyle, Well-Being and Human Development. Vol 6: Mens Sana Monographs; 2008:187-225.

37. van Ginneken V, Sitnyakowsky L, Jeffery JE. Infectobesity: viral infections (especially with human adenovirus-36: Ad-36) may be a cause of obesity. Medical Hypotheses 2009; 72:383-388

38. Atkinson RL, Dhurandhar NV, Allison DB, Bowen RL, Israel BA, Albu JB, Augustus AB. Human adenovirus-36 is associated with increased body weight and paradoxical reduction of serum lipids. International Journal of Obesity 2005; 29:281-286

39. Miwata H, Yamada T, Okada M, Kudo T, Kimura H, Morishima T. SERUM AMYLOID A-PROTEIN IN ACUTE VIRAL-INFECTIONS. Archives of Disease in Childhood 1993; 68:210-214

40. Machida K, Cheng KTH, Sung VMH, Levine AM, Foung S, Lai MMC. Hepatitis $\mathrm{C}$ virus induces toll-like receptor 4 expression, leading to enhanced production of beta interferon and interleukin-6. Journal of Virology 2006; 80:866-874 


\section{Figure 1}

a
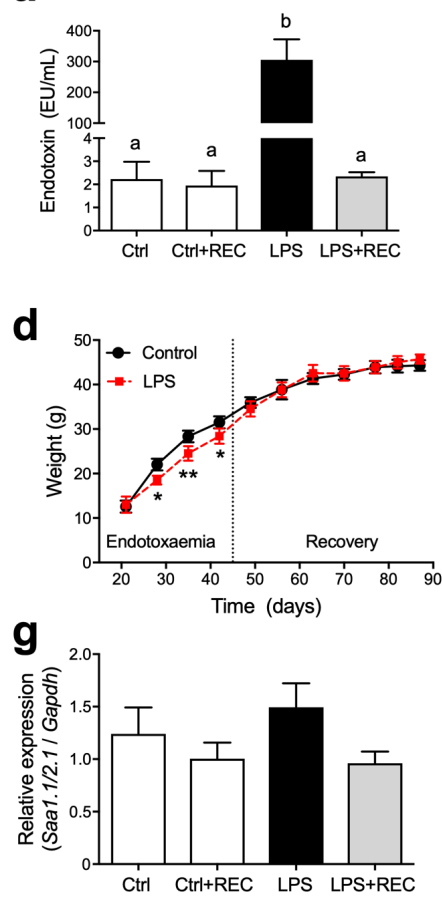

j

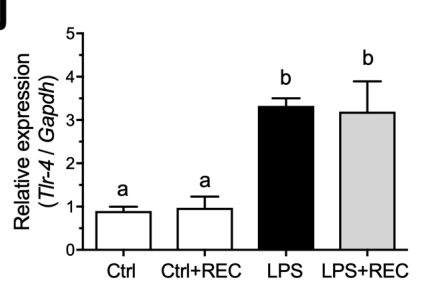

\section{k}

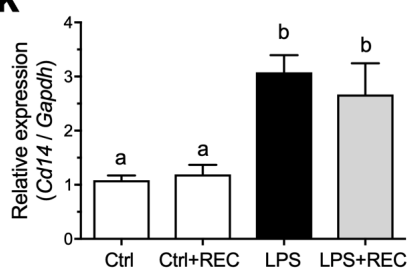

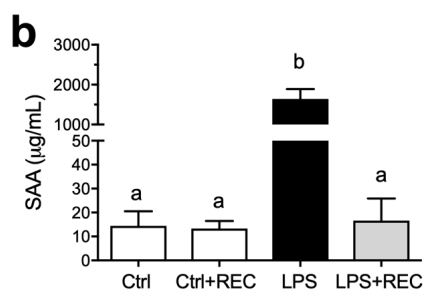

e

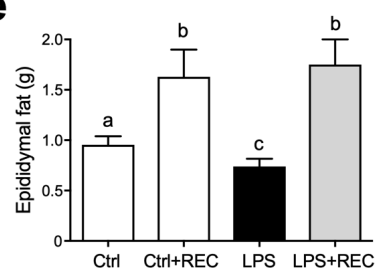

h

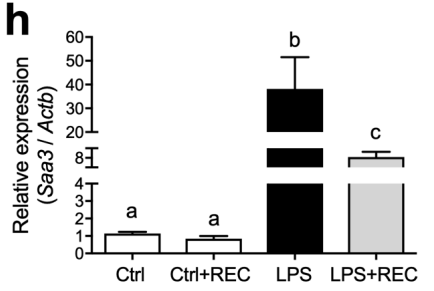

I
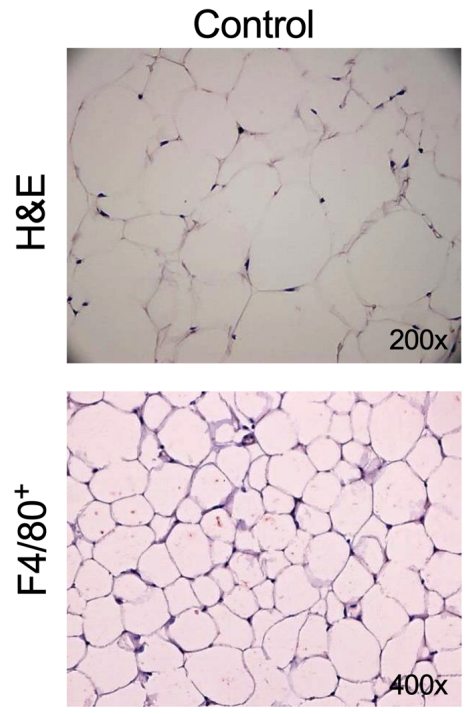

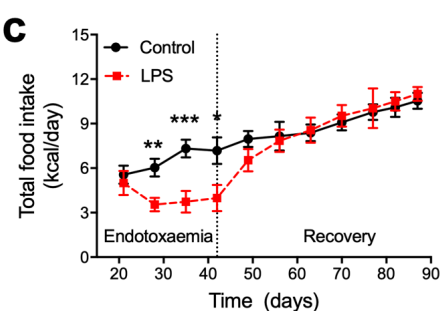

f

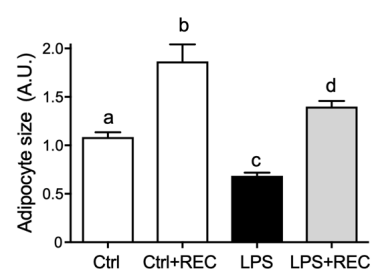

i

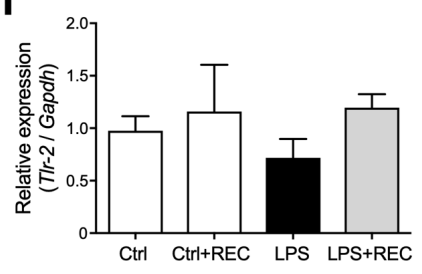

LPS
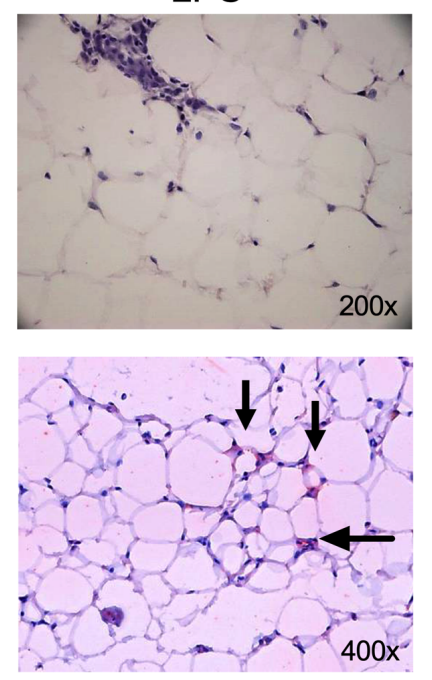


\section{Figure 2}

a

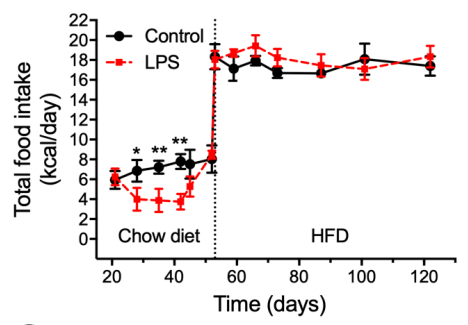

C

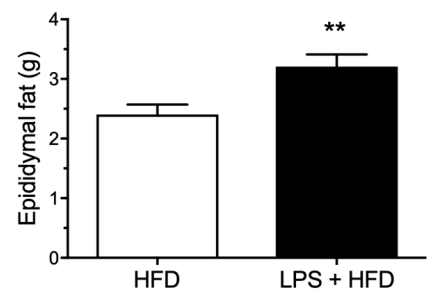

e

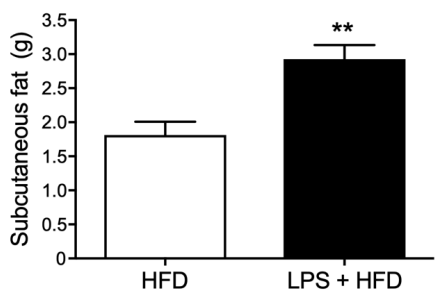

g

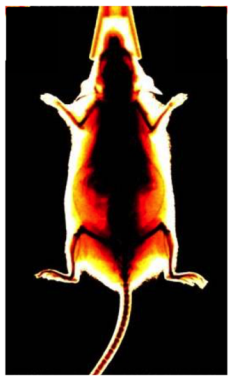

HFD

LPS+HFD b

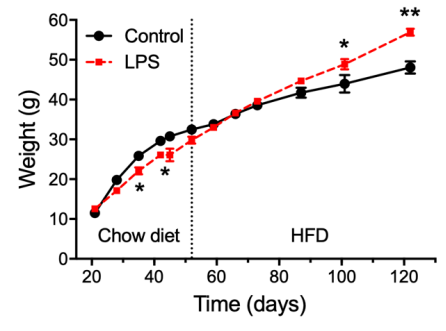

d

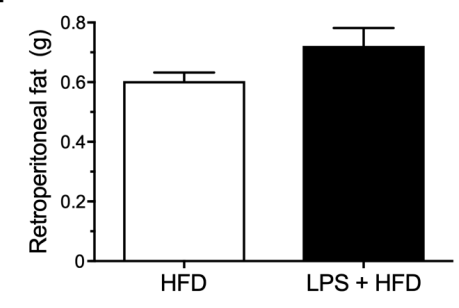

f

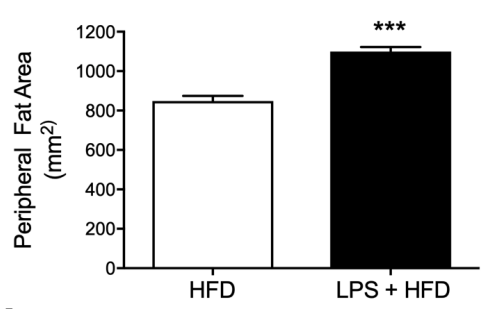

h

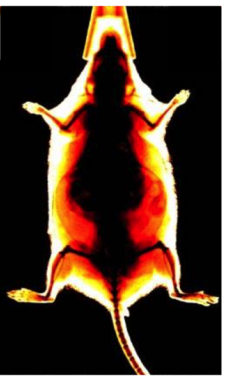

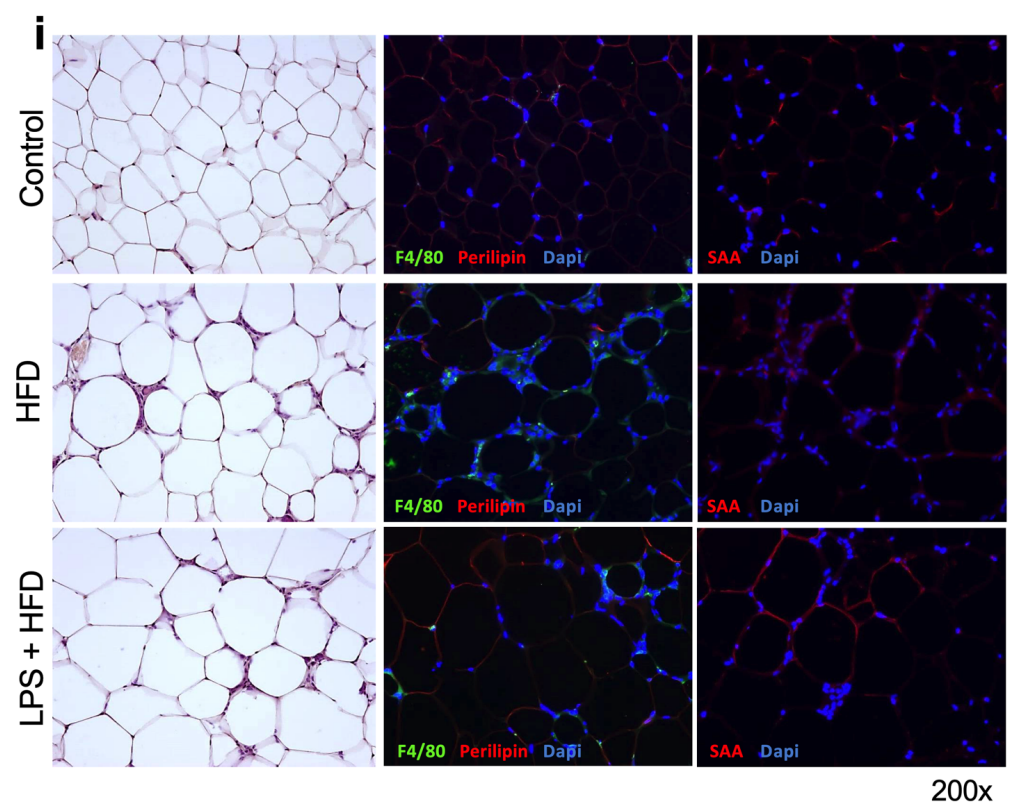


Figure 3

a
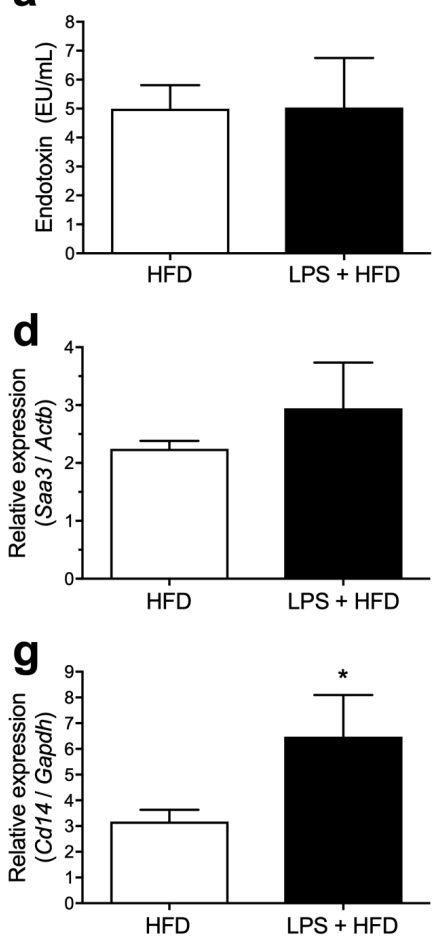

j
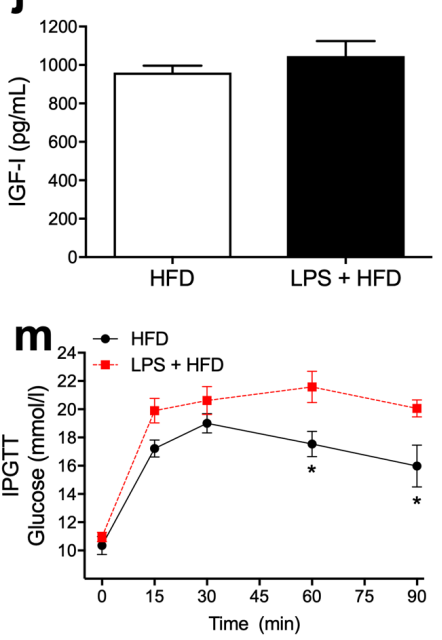

b

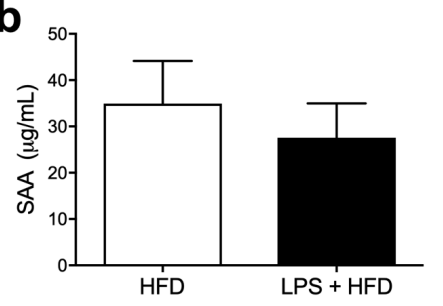

e

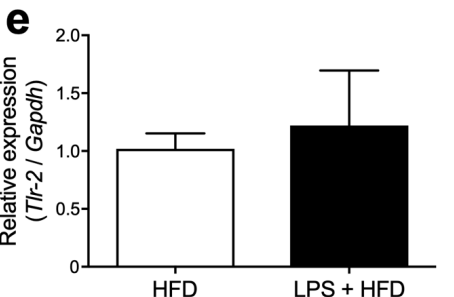

h

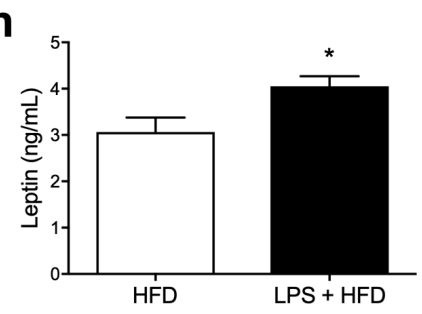

k

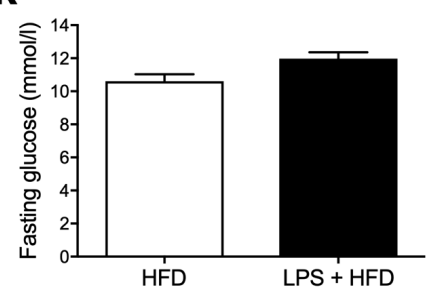

n $-\mathrm{HFD}$

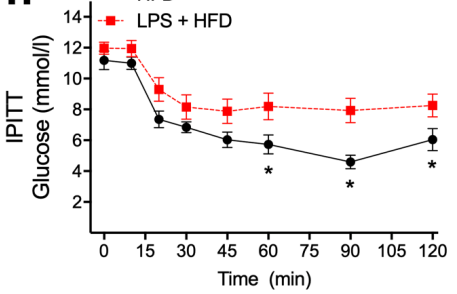

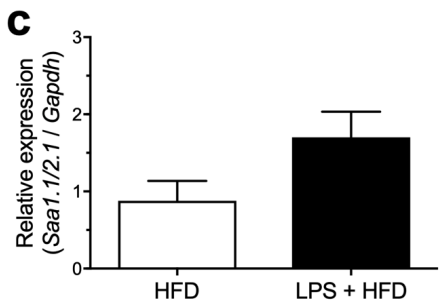
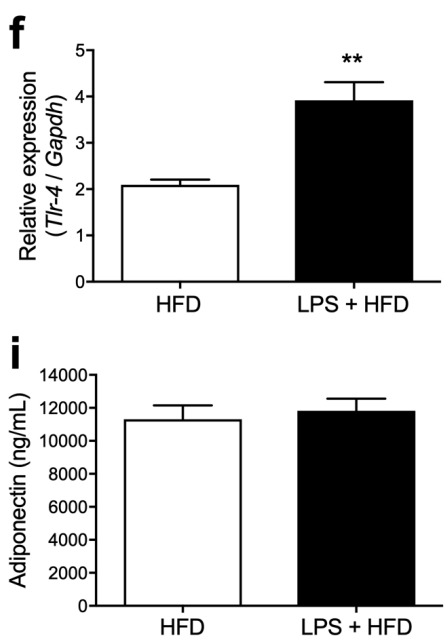

I

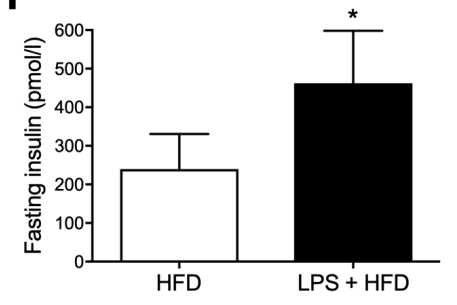


Figure 4

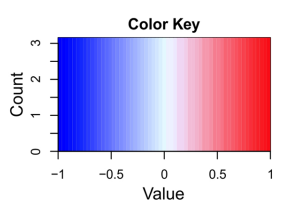

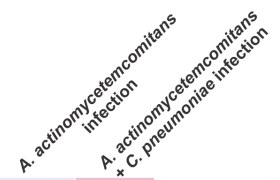

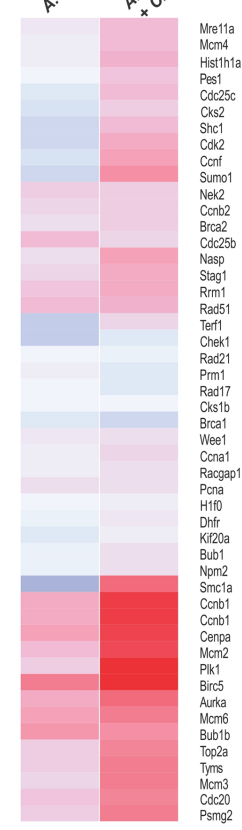

Pro-Proliferative

个 upregulated

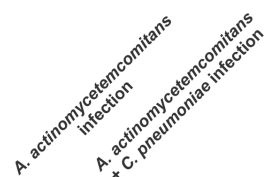

Cfd

Fgf2

Fgf1

Lpl

Fabp4

Acaca

Fas

Jun

Pnpla2

Sfrp5

Dkk1

Sfrp1

Pparg

Adipoq

Cebpb

Cebpd

Acsl1

Cebpa

Plin2

Plin1

SIc2a4

Acacb

Fasn

Pro-Adipogenesis

$\downarrow$ downregulated
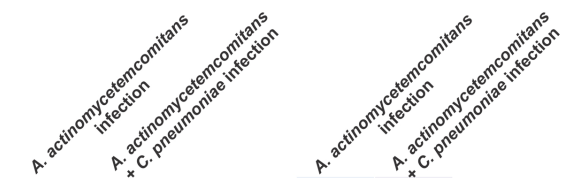

Saa1

Saa2

Saa3

Saa4

Fpr2

TIr2

TIr4

Abca1

Ager

Cd36

Scarb1

Vimp

Abca7

SAA isoforms

and receptors

$\uparrow$ upregulated 